\title{
PENGARUH PERNAFASAN PURSED-LIP SEBELUM LATIHAN FISIK TERHADAP KUALITAS HIDUP PASIEN PENYAKIT PARU OBSTRUKTIF KRONIS (PPOK) DI RUMAH SAKIT PANTIRAPIH YOGYAKARTA
}

\author{
Scholastica Fina Aryu Puspasari ${ }^{1}$ \\ ${ }^{1}$ Akademi Keperawatan Panti Rapih, Jalan Tantular No. 401, Pringwulung, Condong Catur, Sleman, D.I. \\ Yogyakarta. Email: cocolacica@gmail.com
}

\begin{abstract}
Background: Chronic Obstructive Pulmonary Disease (COPD) is a progressive lung illness with the main complaints of breathlessness and decreased activitiestolerance, which consequentially worsen the quality of life (QoL). COPD management aims to improve the QoLby means of rehabilitation programs.

Objective: The study focused on determining the impact of physical activity(6-Minute Walk Test/6-MWT)and the combination of Pursed-Lip Breathing (PLB) before 6-MWTon COPD patients'QoL.

Methods: This study occupieda quasi-experimentaldesign, which involved70 respondents, divided into 3 groups, i.e. 2 intervention groups (30 respondents each) and one control group (10 respondents).

Results:The majority of respondents were male $(71 \%)$, aged $60-74(56 \%)$, had normalBMI $(48 \%)$, and were former smokers (59\%).After 6 weeks of intervention, meaningful differences were found in the QoLbefore and after the intervention in bothgroups:6-MWT $(p=0.000)$ and combined $(p=0.000)$. The ordinal logistic regression test resultedthe combined intervention hadstronger effect on the quality of life ( $p=0.000,47.1 \%$ contribution)than $6-\mathrm{MWT}$ ( $\mathrm{p}=0.012,35.8 \%$ contribution). Respondents' characteristics that impacted on the quality of life were smoking history and period of CPOD ( $p<0.05$, OR: 11,376; OR: 49,75 , respectively).

Conclusion:It can be concluded that PLB before 6-MWT is an effective training to improve QoL of people with COPD.
\end{abstract}

Keywords: pursed-lip breathing; QoL;COPD

\section{PENDAHULUAN}

Penyakit Paru Obstruktif Kronik (PPOK) merupakan penyakit tidak menular yang mempunyai mortalitas dan morbiditas yang tinggi. Mortalitas PPOK mencapai 2,75 juta per tahun dan menduduki peringkat empat tertinggi di dunia setelah kanker, gagal jantung dan stroke. ${ }^{(1)}$ Angka mortalitas tersebut diprediksi akan menjadi penyebab kematian tertinggi nomor tiga di dunia pada tahun $2020^{(2)}$ dan morbiditasnya akan meningkat dari peringkat 12 menjadi peringkat lima penyakit terbanyak di dunia termasuk di Asia. ${ }^{(3)}$
Prevalensi PPOK di Asia diperkirakan mencapai 6,3\% sementara di Indonesia diperkirakan mencapai 5,6\%. ${ }^{(3)}$ Peningkatan prevalensi PPOK di Indonesia dipengaruhi tingginya masyarakat perokok dan peningkatan Usia Harapan Hidup (UHH). Salah satu kota yang memiliki $\mathrm{UHH}$ yang tinggi adalah Yogyakarta yaitu 74 tahun. Peningkatan prevalensi PPOK di Yogyakarta diperkirakan mencapai $200 \%$ dalam tujuh tahun terakhir, yaitu dari 1.514 jiwa pada tahun $2006^{(4)}$ menjadi 3.100 jiwa pada tahun 2013. ${ }^{(5)}$ Peningkatan prevalensi penderita PPOK tersebut juga dialami oleh Rumah Sakit Panti 
Rapih yang merupakan salah satu rumah sakit di Yogyakarta. Prevalensi PPOK di RS tersebut pada tahun 2012-2014 sebanyak 1.074 orang.

Keluhan sesak nafas dan intoleransi aktivitas merupakan keluhan utama pada pasien PPOK. ${ }^{(3)}$ Keluhan sesak nafas pada pasien PPOK bersifat progresif, irreversible, dan menurunkan toleransi dalam beraktivitas. ${ }^{(6)}$ Keluhan sesak nafas dan intoleransi aktivitas tersebut akan menurunkan tingkat kemandirian dan berdampak terhadap kualitas hidup.

Penurunan kualitas hidup pada pasien PPOK didukung oleh hasil penelitian yang dilakukan oleh Reherison ${ }^{(7)}$ di Prancis pada tahun 2009 - 2010 terhadap 400 penderita PPOK yang berusia lebih dari 40 tahun. Hasil penelitian tersebut menunjukkan bahwa PPOK mempengaruhi penurunan kualitas hidup pada $50,6 \%$ responden dengan nilai $p<0,02$. Penurunan kualitas hidup pada pasien PPOK tersebut paling banyak dipengaruhi oleh penurunan toleransi beraktivitas.

Peningkatan toleransi aktivitas diharapkan dapat meningkatkan kualitas hidup pasien PPOK melalui peningkatan kemandirian pasien. Peningkatan toleransi aktivitas dapat dilakukan melalui rehabilitasi, dimana Perhimpunan Dokter Paru Indonesia $\left(\right.$ PDPI) ${ }^{(3)}$ menekankan bahwa rehabilitasi pada pasien PPOK dilakukan melalui latihan fisik dan latihan pernafasan. Global Strategy For The Diagnosis, Management, and Prevention of Chronic Obstructive Pulmonary Disease
$(G O L D)^{(8)}$ merekomendasikan latihan fisik yang paling tepat dilakukan pada pasien PPOK adalah latihan fisik six minute walk test (6MWT). Kendala utama latihan fisik pada pasien PPOK adalah sesak nafas. ${ }^{(3)}$ Sesak nafas pada pasien PPOK terjadi karena air-trapping atau terperangkapnya udara ke dalam paru-paru. Salah satu latihan pernafasan paling efektif dalam menurunkan air-trapping adalah melalui pernafasan pursed-lip (PLB).

Berdasarkan latar belakang tersebut, pertanyaan pada penelitian ini adalah bagaimana pengaruh PLB sebelum latihan fisik 6-MWT terhadap kualitas hidup pasien PPOK. Pada penelitian ini, peneliti akan melihat pengaruh PLB sebelum latihan fisik 6-MWT terhadap kualitas hidup pasien PPOK.

\section{BAHAN DAN CARA PENELITIAN}

Penelitian ini merupakan penelitian kuantitatif dengan rancangan kuasi eksperimen pretest dan posttest pada dua kelompok perlakuan untuk mengetahui pengaruh PLB sebelum 6-MWT terhadap kualitas hidup responden PPOK. Penelitian dilakukan di Poliklinik Spesialis Paru Rumah Sakit Panti Rapih Yogyakarta pada bulan April sampai dengan Juni 2015 yang melibatkan 70 responden dengan menggunakan teknik random. Responden terbagi menjadi tiga kelompok, yaitu dua kelompok intervensi masing-masing 30 responden dan 10 responden sebagai kontrol. Responden dipilih 
berdasarkan kriteria menderita PPOK derajat sedang, berat, dan sangat berat menurut GOLD, tidak dalam eksaserbasi akut, dan tidak sedang menjalani terapi pernafasan.

Responden yang terpilih secara acak pada latihan fisik 6-MWT diajarkan latihan 6-MWT dengan tepat dan pada responden yang terpilih untuk masuk dalam kelompok intervensi kedua, peneliti mengajarkan prosedur PLB dan latihan 6-MWT, kemudian meminta keluarga untuk mengobservasi pelaksanaannya di rumah dengan lembar observasi yang disediakan oleh peneliti. Pada kelompok kontrol, peneliti tidak melakukan intervensi, namun hanya membagikan leaflet yang berisi konsep penyakit PPOK. Pengambilan data awal dilakukan selama 3 minggu, meliputi identitas responden, fungsi paru, dan kuesioner kualitas hidup yang diperoleh dengan menggunakan instrumen St. George Respiratory Questionnaire (SGRQ).

Intervensi dilakukan selama enam minggu dengan observasi oleh peneliti dan asisten peneliti. Pada prosedur latihan fisik 6-MWT, responden melakukan latihan jalan santai pada lantai yang datar selama enam menit setiap hari, dan pada prosedur gabungan PLB dengan 6-MWT, responden melakukan latihan pernafasan pursed-lip 5-10 menit sebelum melakukan 6-MWT.

Pada minggu yang ketujuh, peneliti mengumpukan data akhir (post test) meliputi data kualitas hidup berdasarkan SGRQ dengan menghubungi masing-masing responden melalui telepon. Data yang diperoleh kemudian dianalisis menggunakan uji pengaruh, uji beda berpasangan, dan uji beda independen pada masing-masing kelompok.

\section{HASIL DAN PEMBAHASAN}

Tabel 1 Karakteristik Responden $(\mathrm{N}=70)$

\begin{tabular}{|c|c|c|c|}
\hline No & Karakteristik & $f$ & $\%$ \\
\hline \multirow[t]{4}{*}{1} & Usia & & \\
\hline & $45-59$ & 9 & 13 \\
\hline & $60-74$ & 39 & 56 \\
\hline & $>74$ & 22 & 31 \\
\hline \multirow[t]{3}{*}{2} & Jenis kelamin & & \\
\hline & Laki-laki & 50 & 71 \\
\hline & Perempuan & 20 & 29 \\
\hline \multirow[t]{4}{*}{3} & $\begin{array}{l}\text { Indeks massa } \\
\text { tubuh (IMT) }\end{array}$ & & \\
\hline & Under-weight & 30 & 43 \\
\hline & Normal & 34 & 48 \\
\hline & Over-weight & 6 & 9 \\
\hline \multirow[t]{4}{*}{4} & $\begin{array}{l}\text { Tingkat } \\
\text { pendidikan }\end{array}$ & & \\
\hline & Rendah & 25 & 36 \\
\hline & Menengah & 28 & 40 \\
\hline & Tinggi & 17 & 24 \\
\hline \multirow[t]{4}{*}{5} & $\begin{array}{l}\text { Tingkat sosial } \\
\text { ekonomi }\end{array}$ & & \\
\hline & Rendah & 35 & 50 \\
\hline & Menengah & 30 & 43 \\
\hline & Tinggi & 5 & 7 \\
\hline \multirow[t]{5}{*}{6} & $\begin{array}{l}\text { Riwayat } \\
\text { merokok }\end{array}$ & & \\
\hline & Bukan Perokok & 10 & 14 \\
\hline & Bekas Perokok & 41 & 59 \\
\hline & Perokok Pasif & 17 & 24 \\
\hline & Perokok Aktif & 2 & 3 \\
\hline \multirow[t]{3}{*}{7} & $\begin{array}{l}\text { Penyakit paru } \\
\text { lain }\end{array}$ & & \\
\hline & Ada & 6 & 8 \\
\hline & Tidak ada & 64 & 92 \\
\hline
\end{tabular}


Berdasarkan Tabel 1, diketahui bahwa mayoritas responden adalah laki-laki (72\%), berusia 60 - 74 tahun (52\%), IMT underweight (50\%), berpendidikan SMA sederajat (42\%), tingkat sosial ekonomi rendah (50\%), bekas/mantan perokok (63\%), tidak mempunyai penyakit paru lain (92\%), menderita PPOK dalam waktu 1 sampai 5 tahun (49\%).

Tabel 2

Hasil Uji Beda Berpasangan

\begin{tabular}{lll}
\hline No & \multicolumn{1}{c}{ Kelompok } & p value \\
\hline 1 & Latihan fisik 6-MWT & 0,000 \\
2 & $\begin{array}{l}\text { PLB sebelum latihan fisik 6- } \\
\text { MWT }\end{array}$ & 0,000 \\
& & \\
\hline
\end{tabular}

Berdasarkan Tabel 2, didapatkan nilai $p<0,05$ pada kedua kelompok. Ini menunjukkan bahwa secara statistik ada perbedaan kualitas hidup yang signifikan sebelum intervensi dengan sesudah intervensi pada kedua kelompok intervensi.

Tabel 3

Hasil Uji Beda Independen

\begin{tabular}{lll}
\hline No & \multicolumn{1}{c}{ Kelompok } & p value \\
\hline 1 & $\begin{array}{l}\text { Latihan fisik 6-MWT dengan } \\
\text { PLB sebelum latihan fisik 6- } \\
\text { MWT }\end{array}$ & 0,022 \\
2 & $\begin{array}{l}\text { Latihan fisik 6-MWT dengan } \\
\text { kontrol }\end{array}$ & 0,005 \\
3 & $\begin{array}{l}\text { PLB sebelum latihan fisik 6- } \\
\text { MWTdengan kontrol }\end{array}$ & 0,000
\end{tabular}

Berdasarkan Tabel 3, diketahui bahwa ada perbedaan yang bermakna pada kualitas hidup antara kelompok intervensi lathan fisik 6-MWT dengan PLB sebelum latihan fisik 6$\operatorname{MWT}(p=0,022) ; \quad$ antara kelompok intervensilatihan fisik 6-MWT dengan kontrol $(p=0,005)$; dan antara kelompok intervensi PLB sebelum latihan fisik 6-MWTdengan kontrol $(p=0,000)$.

\section{Tabel 4}

Uji Pseudo R-Square Antar Kelompok Intervensi

\begin{tabular}{lc}
\hline Kelompok Intervensi & Cox and Snell \\
\hline Latihan fisik 6-MWT & 0,358 \\
\hline PLB sebelum latihan & 0,471 \\
fisik 6-MWT & \\
\hline
\end{tabular}

Berdasarkan tabel 4, disimpulkan bahwa kelompok yang memberikan kontribusi paling besar terhadap variabel dependen adalah kelompok intervensi PLB sebelum latihan fisik 6-MWTsebesar 47,1\%. Artinya intervensi PLB sebelum latihan fisik 6-MWT secara simultan memberikan kontribusi yang paling besar terhadap kualitas hidup.

\section{Tabel 5}

\begin{tabular}{lrr}
\multicolumn{1}{c}{$\begin{array}{c}\text { Perbandingan Besarnya Pengaruh Setiap } \\
\text { Intervensi Terhadap Kualitas Hidup }\end{array}$} \\
\hline \multicolumn{1}{|c}{ Kelompok } & $\begin{array}{c}\text { Hasil Parameters } \\
\text { Estimates } \\
\text { Estimate }\end{array}$ & Nilai p \\
\hline Latihan fisik 6-MWT & $-2,342$ & 0,012 \\
$\begin{array}{l}\text { PLB sebelum } \\
\text { latihan fisik 6-MWT }\end{array}$ & $-3,806$ & 0,000 \\
\hline
\end{tabular}

Berdasarkan Tabel 5, didapatkan nilai $p<0,05$ pada semua kelompok sehingga secara 
statistik dapat disimpulkan bahwa semua intervensi memberikan pengaruh secara signifikan terhadap kualitas hidup. Dilihat dari besarnya estimate didapatkan nilai estimate tertinggi pada kelompok intervensi PLB sebelum latihan fisik 6-MWT yaitu 3,806. Secara statistik disimpulkan bahwa gabungan intervensi PLB sebelum latihan fisik 6-MWT memberikan pengaruh paling besar terhadap kualitas hidup pasien PPOK dibandingkan intervensi tunggal 6-MWT.

Intervensi ini dikatakan berpengaruh, sebab intervensi ini mencoba mengatasi gangguan intrapulmonal pada pasien PPOK yang termanifestasi dalam keluhan sesak nafas dan gangguan ekstrapulmonal berupa disfungsi otot skeletal. ${ }^{(9)}$

Latihan 6-MWT secara teori dapat membantu meningkatkan kualitas hidup dengan meningkatkan toleransi aktivitas. Latihan 6-MWT dapat meningkatkan fungsi cardiopulmonal dan melatih kerja sistem muskuloskeletal terutama pada kaki sehingga akan mencegah peripheral muscle wasting. Analisis peneliti ini sesuai dengan pernyataan yang disampaikan oleh Criner $^{(10)}$ bahwa peripheral muscle wasting dapat diatasi dengan latihan kekuatan otot kaki, salah satunya dengan 6-MWT. Peningkatan status fungsional ini akan meningkatkan pemenuhan kebutuhan aktivitas dan pencegahan terhadap bahaya menurut teori self-care dari Orem. ${ }^{(11)}$
Latihan PLB sebagai salah satu intervensi dalam penelitian ini bertujuan memperbaiki efektivitas pernafasan dengan menurunkan airtrapping sehingga dapat meningkatkan volume tidal dan memperbaiki kontrol pernafasan. PLB dapat meningkatkan efisiensi bernafas dengan meningkatkan kemampuan ekshalasi sehingga menurunkan jumlah udara yang tertinggal dalam paru.

Intervensi PLB sebelum latihan fisik 6MWT akan membantu memperbaiki peningkatam fungsi fisik. Analisis peneliti ini didukung oleh pernyataan Yancey ${ }^{(12)}$ bahwa PLB digabungkan dengan 6-MWT akan meningkatkan toleransi latihan pada pasien PPOK. Hal ini dibuktikan pula dengan hasil penelitian Niedl ${ }^{(13)}$ mengenai efektivitas latihan 6-MWT dan latihan pernafasan yang melibatkan 53 pasien PPOK di klinik paru University-Affiliated Veteran Affairs. Hasil penelitian menunjukkan bahwa pada kelompok yang diberikan latihan pernafasan sebelum melakukan aktivitas mengalami penurunan keluhan sesak nafas $(p=0,05)$ dan terjadi peningkatan toleransi latihan $(p=0,02)$. Pemenuhan toleransi latihan akan meningkatkan pemenuhan dalam kebutuhan aktivitas. Pemenuhan kebutuhan aktivitas merupakan kebutuhan universal self-care menurut Orem. Artinya, kedua kebutuhan tersebut merupakan kebutuhan dasar dari setiap manusia. Pemenuhan kebutuhan universal self-care tersebut akan meningkatkan 
pemeliharaan proses hidup, integritas struktural dan fungsi hidup, yang berdampak terhadap tingkat kemandirian dan kualitas hidup individu.

\section{KESIMPULAN}

Berdasarkan uji statistik diketahui bahwa intervensi PLB sebelum latihan fisik 6-MWT memberikan pengaruh paling kuat terhadap kualitas hidup dibandingkan hanya melakukan latihan fisik 6-MWT saja.

Peneliti merekomendasikan perlunya mengajarkan dan memberikan edukasi pentingnya latihan PLB sebelum latihan fisik, serta penelitian lanjut terkait kondisi psikologis terhadap kualitas hidup pasien PPOK.

\section{UCAPAN TERIMAKASIH}

1. dr. Teddy janong, M.Kes (Direktur Rumah Sakit panti rapih)
2. Bapak
Paulus
Subiyanto, S.Kp.,M.Kep.,Sp.KMB (Direktur Akper Panti rapih)

\section{KEPUSTAKAAN}

1. Harwood, M. Diagnosis and Management of COPD in Maori and Pacific Peoples. BPJ Issue 2012; 43: 15 - 25.

2. Lewis : Medical-Surgical Nursing: Assessment and Management of Clinical Problems. St. Louis, Missouri: Elsevier Mosby; 2011.

3. Perhimpunan Dokter Paru Indonesia : PPOK (Penyakit Paru Obstruktif Kronik): Diagnosis dan Penatalaksanaan. Jakarta: Perhimpunan Dokter Paru Indonesia; 2011.
4. Patriani, A. P. Pemberdayaan Keluarga dalam Rehabilitasi Medik Pada Penderita Penyakit Paru Obstruksi Kronik di Balai Pengobatan Penyakit Paru-Paru Yogyakarta. Berita Kedokteran Masyarakat $2010: 26 ; 55$ - 62.

5. Riskesdas. Penyajian Pokok-Pokok Hasil dan Riset Kesehatan Dasar 2013. Badan Penelitian dan Pengembangan Kesehatan Kementerian Kesehatan RI; 2013.

6. Kendall : Sinopsis Organ Sistem Pulmonologi: Pendekatan dengan Sistem Terpadu dan Disertai Kumpulan Kasus Klinik. Bandung: Karisma Publishing Group; 2014.

7. Reherison, Crantal. Clinical Characteristic and Quality of Life in Women with COPD. BMC Women's Health Journal 2014; 14:31

8. GOLD. Global Strategy For The Diagnosis, Management, and Prevention of Chronic Obstructive Pulmonary Disease. Global Initative for Chronic Obstructive Lung Disease2014; 1-100.

9. Valero, M. Types of Physical Exercise Training for COPD Patients. Intechopen Journal 2012: 352-374.

10. Criner, G. 6-Minute Walk Testing in COPD: Is It Reproducible? European Respiratory Journal 2011; 244-5.

11. McEwen : Theoretical Basis forNursing: Second Edition. Philadelphia: Lippincott Williams \& Wilkins; 2007.

12. Yancey, J. C. The Role of Breathing Exercises in the Treatment of COPD. American Family Phisician2014: 15-16.

13. Niedl, M. Efficacy of Pursed-Lip Breathing: Efficacy of Pursed-Lips Breathing: a Breathing Pattern Retraining Strategy for Dyspnea Reduction.. Journal of Cardiopulmonary Rehabilitation and Prevention 2007: 237-44. 